\title{
Functional Specificity of Mossy Fiber Innervation of GABAergic Cells in the Hippocampus
}

\author{
János Szabadics and Ivan Soltesz \\ Department of Anatomy and Neurobiology, University of California, Irvine, Irvine, California 92697
}

One million mossy fibers in the rat provide individually sparse but functionally important synaptic connections between the dentate gyrus and hippocampus. Although the majority of mossy fiber targets are GABAergic cells, the functional organization of the feedforward GABAergic machinery modulating the interactions of granule cells and CA3 pyramidal cells are not yet understood. We used mossy fiber bouton to GABA neuron paired recordings in the CA3 to demonstrate that mossy fibers provide cell type-specific innervation to distinct GABAergic neurons with specialized intra- and extrahippocampal outputs. Our results show that mossy fibers contact the perisomatically projecting fast-spiking and regular-spiking basket cells, in addition to the dendritically projecting ivy cells, and the septum-projecting spiny stratum lucidum cells. Monosynaptic mossy fiber inputs to fast-spiking basket cells and spiny stratum lucidum cells were found to be numerous, but they were small in amplitude and displayed low transmission probabilities. In contrast, regular-spiking basket cells and ivy cells were less likely to be innervated by mossy fibers, but the amplitudes of mossy fiber EPSCs were large and the transmission probabilities were high. The dependence of the numbers and strengths of the mossy fiber inputs to CA3 GABAergic cells on the postsynaptic cell type was correlated with the frequency of the background synaptic events, so that cells with weak but numerous mossy fiber inputs received high rates of spontaneous synaptic events. Together, these results reveal the diverse components and high degree of functional specificity of the GABAergic cellular machinery underlying the dentate gyrus-CA3 interface.

\section{Introduction}

Information carried by mossy fibers (MFs) from the dentate gyrus (DG) to the hippocampus is implicated in key memory and spatial representation functions, including the disambiguation of small differences in cortical inputs (referred to as pattern separation) (Nakazawa et al., 2004; Leutgeb et al., 2007; Bakker et al., 2008; Nakashiba et al., 2008). Granule cells, the principal neurons of the DG, are excitatory cells with unique properties (Ylinen et al., 1995; Henze et al., 2002; Hahn et al., 2007; Leutgeb et al., 2007). Their highly specialized axonal output, the MFs (Frotscher et al., 2006; Rollenhagen et al., 2007), provide strong synaptic excitation to CA3 pyramidal cells, with the short- and long-term plasticity mechanisms involved in the MF-mediated excitation of target cells being distinct from the mechanisms involving inputs originating from other sources, including those from local pyramidal cells (Williams and Johnston, 1991; Jonas et al., 1993; Nicoll and Malenka, 1995; Salin et al., 1996; Maccaferri et al., 1998; Min et al., 1998; Nicoll and Schmitz, 2005; Pelkey et al., 2006). MFs form two major types of synapse in the stratum lucidum of the CA3, and these two types display a high degree of target selectivity and functional specialization. Namely, the un-

Received Nov. 6, 2008; revised Feb. 5, 2009; accepted March 2, 2009.

This work was supported by National Institutes of Health Grant NS35915 and the George E. HewittFoundation for Medical Research. We thank Rose Zhu and Dóra Hegedüs for technical assistance, Matthew Turner for expert advice in statistical analysis, Dr. Csaba Varga for advice on antibodies, Drs. Csaba Földy and Robert Morgan for their comments on this manuscript, and Dr. Steven Ross for the generous loan of a Nikon Eclipse FN1 microscope.

Correspondence should be addressed to Dr. János Szabadics, Department of Anatomy and Neurobiology, University of California, Irvine, 193 Irvine Hall, Irvine, CA 92697-1280. E-mail: szabadics.janos@uci.edu.

DOI:10.1523/JNEUROSCI.5390-08.2009

Copyright $\odot 2009$ Society for Neuroscience $\quad$ 0270-6474/09/294239-13\$15.00/0 usually large (3-6 $\mu \mathrm{m}$; so-called "giant") MF terminals innervate primarily pyramidal cells, whereas small filopodia emanating from the giant terminals and small en passant boutons contact GABAergic cells (Acsády et al., 1998). Since single MFs contact more GABAergic targets (30-50) than do CA3 pyramidal cells $(10-20)$ [note that these uniquely low numbers indicate the unusual sparsity of the synaptic outputs from single granule cells (Acsády et al., 1998)], the excitation of GABAergic cells by granule cells is likely to be a significant regulator of the output of CA3 pyramidal cells (Tóth and McBain, 1998; Lawrence and McBain, 2003; Mori et al., 2004, 2007; Pelkey and McBain, 2008). However, the types of CA3 GABAergic cells targeted by MFs and the physiological properties of MF inputs onto distinct types of GABAergic cells are not well understood. The relative paucity of precise information concerning the identity of MF GABAergic targets and the cell type-specific properties of the MF synaptic inputs to distinct GABAergic cells in the CA3 is primarily attributable to the fact that it has been prohibitively difficult to obtain paired recording data in acute hippocampal slices from synaptically connected granule cells and CA3 GABAergic neurons, because of the large distance between the DG and CA3, and because each granule cell provides only a single MF collateral in the CA3 (Acsády et al., 1998) [note that granule cell to CA3 GABAergic cell pair recordings have been obtained in organotypic slice cultures (Mori et al., 2004, 2007)].

Here we combined presynaptic MF bouton recordings (Bischofberger et al., 2006b) with recordings from postsynaptic, post hoc identified CA3 GABAergic cells to deepen our understanding of how distinct hippocampal feedforward inhibitory cells are synaptically innervated by single MFs. The results show 
that MFs provide monosynaptic innervation to four anatomically well defined GABAergic cell types in the CA3, including both perisomatically and dendritically projecting cells. Importantly, MF targets include GABAergic cells with exclusively intra-CA3 axonal outputs (i.e., "interneurons" in the classical sense), as well as GABAergic cells that project to extrahippocampal areas, including the medial septum and, surprisingly, the DG itself. Finally, our results show that MF inputs to GABAergic cells are not randomly distributed, but show strong cell type-dependent properties concerning both the probability and strength of the MF-to-GABAergic cell connections.

\section{Materials and Methods}

Our experimental protocols were approved by the Institutional Animal Care and Use Committee of the University of California, Irvine.

Recording and analysis of monosynaptic mossy fiber connections to CA3 GABAergic cells in acute slices. Slices were prepared from adolescent rats (postnatal day 21-30) deeply anesthetized with isoflurane, using an orientation in which the majority of the MFs and dendrites of CA3 pyramidal cells were parallel to the surface of the slice and thus were better preserved (described in detail by Bischofberger et al., 2006b) [note that the slices were taken from the middle third of the hippocampal formation; also note that single mossy fibers have restricted distribution in the septo-temporal axis, and they remain in the hippocampal lamella where their parent cell bodies reside (Freund and Buzsáki, 1996; Acsády et al., 1998)]. Slices were prepared in icecold artificial CSF [consisting of (in mM): 85 $\mathrm{NaCl}, 75$ sucrose, $2.5 \mathrm{KCl}, 25$ glucose, 1.25 $\mathrm{NaH}_{2} \mathrm{PO}_{4}, 4 \mathrm{MgCl}_{2}, 0.5 \mathrm{CaCl}_{2}$, and 24 $\mathrm{NaHCO}_{3}$ ), and transferred to a holding chamber that was kept at room temperature, until the slices were used for recordings. Slices were visualized with an upright microscope (Eclipse FN-1; Nikon) with infrared (750 nm) Nomarski differential interference contrast optics [Nikon $40 \times$ NIR (near infrared) Apo N2 NA0.8W WD3.5 objective with $1.5 \times, 2 \times$ magnification lenses). Recording solution was composed of (in $\mathrm{mm}$ ): $126 \mathrm{NaCl}, 2.5 \mathrm{KCl}, 26 \mathrm{NaHCO}_{3}, 2$ $\mathrm{CaCl}_{2}, 2 \mathrm{MgCl}_{2}, 1.25 \mathrm{NaH}_{2} \mathrm{PO}_{4}$, and 10 glucose. Electrophysiological recordings were performed at $36 \pm 0.5^{\circ} \mathrm{C}$. For somatic whole-cell recordings from CA3 GABAergic cells, pipettes were filled with an intracellular solution containing (in $\mathrm{mm}$ ): 90 potassium gluconate, $43.5 \mathrm{KCl}, 1.8$ $\mathrm{NaCl}, 1.7 \mathrm{MgCl}_{2}$, 0.05 EGTA, 10 HEPES, $2 \mathrm{Mg}$-ATP, $0.4 \mathrm{Na}_{2}$-GTP, 10 phosphocreatine, and 8 biocytin, $\mathrm{pH} 7.2$ (270-290 mOsm; pipette resistance: $3-4.5 \mathrm{M} \Omega$ ) (note that this intracellular solution was used because our preliminary experiments showed that it yielded the most stable longterm recordings). For recordings from MF terminals, the same intracellular solution was used as for the GABAergic cell (pipette resistance, 8-12 $M \Omega$ ), except that the whole-bouton pipette in most cases lacked biocytin to avoid overloading the slices with nonspecific staining. The chemicals listed above were purchased from Sigma.

We applied MF-terminal-to-GABAergic-cell paired recordings (Fig. $1 A$ ) to determine which CA3 GABAergic cell types are monosynaptically excited by single MFs and to establish whether MFs provide cell type-
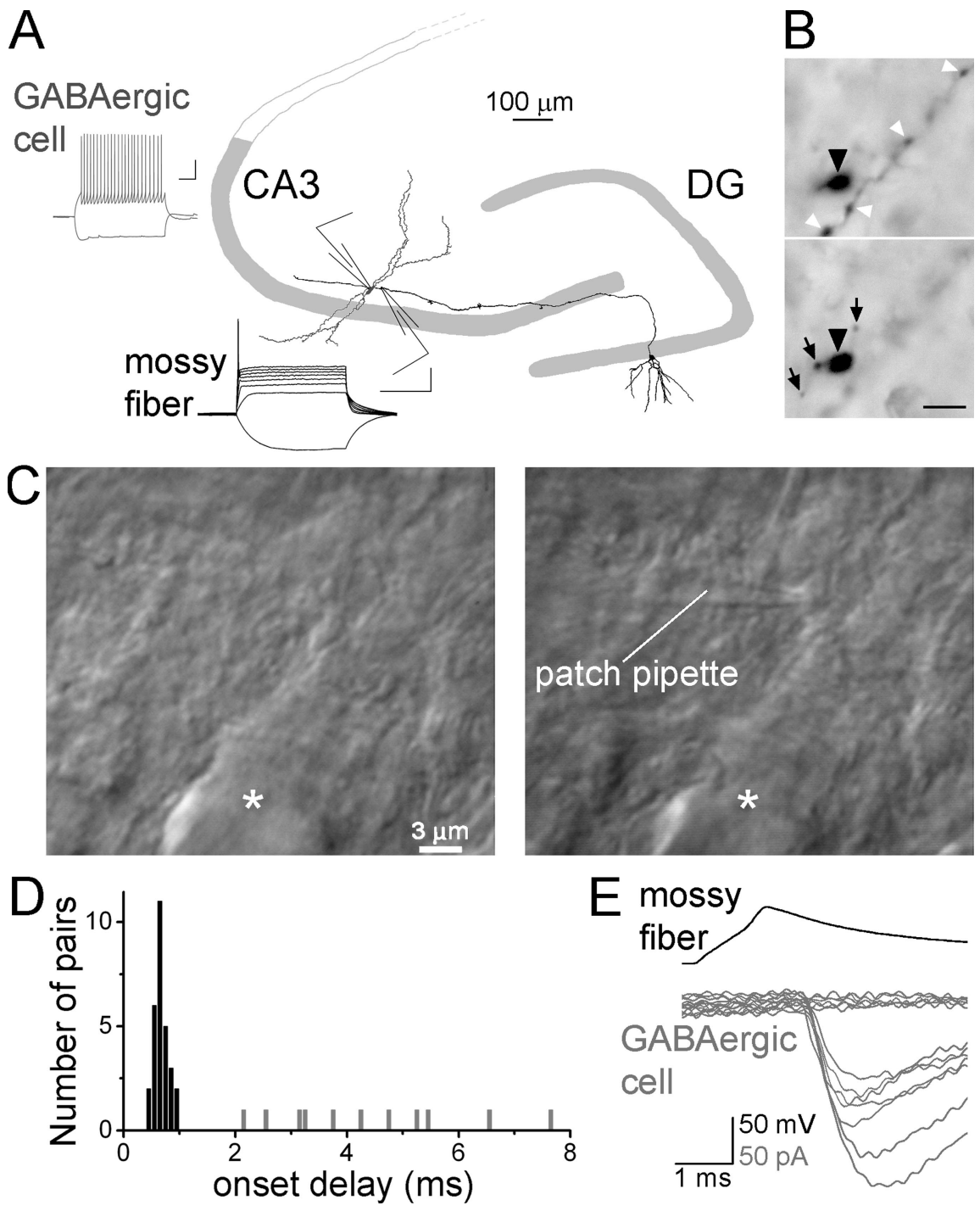

Figure 1. Simultaneous recording of MFs and CA3 GABAergic cells. $\boldsymbol{A}$, Schematic of MF terminal-GABAergic cell pair recording with a camera lucida drawing of a granule cell (black) back-filled through the recorded single bouton with biocytin; the dendrites of a GABAergic cell (gray) simultaneously recorded with the MF is also illustrated (traces: examples of MF and GABAergic cell ( Scale bar, $5 \mu \mathrm{m}$. C, Differential interference contrast image of a giant MF terminal on the apical dendrite of a CA3 to the EPSC onset) for individual monosynaptic (dark bars) and polysynaptic (gray) pairs. $\boldsymbol{E}$, Example traces from a monosynaptically coupled MF (presynaptic action potentials; top, black) to GABAergic cell pair (MF-EPSCs and failures; bottom, gray).

specific EPSCs to GABAergic cells in the CA3 region. To obtain paired recordings between MFs and CA3 GABAergic cells, somatic whole-cell patch-clamp recordings were made first from GABAergic cells in the $\mathrm{CA} 3 \mathrm{~b}$ in or near the stratum lucidum (the termination zone of MFs). Once a stable whole-cell recording was obtained from a putative GABAergic cell, MF giant boutons (size: 3-6 $\mu \mathrm{m}$ ) were "whole-bouton" patched in the stratum lucidum within $50 \mu \mathrm{m}$ of the GABAergic cell (Fig. $1 \mathrm{~A}-\mathrm{C}$ ) (Bischofberger et al., 2006b) (note that the latter recording arrangement cannot sample MF inputs to GABAergic cells whose cell bodies are not located in relative proximity to the MF termination zone; the sampled GABAergic cells were in strata pyramidale, lucidum, and proximal radiatum). Giant MF boutons mostly innervate pyramidal cells in the CA3, and GABAergic cells are contacted predominantly by small filopodial and small en passant terminals (Frotscher, 1985; Acsády et al., 1998). Because we were recording from the large terminals, our paired recording approach did not aim to record the terminals that were directly involved in the synaptic transmission between the MFs and postsynaptic 
GABAergic cells. Instead, the goal of technique was to provide electrophysiological control of single MFs in the proximity of the simultaneously recorded GABAergic cells (note that, because our presynaptic recording was made from the giant terminals, it cannot be excluded that this approach may undersample MFs with unusually low number of giant terminals; however, the existence of such MFs is not known). Identification of MF boutons was primarily based on their unique electrophysiological properties, including fast whole-cell membrane capacitance (noncompensated) artifact in whole-bouton voltage-clamp recordings, extremely slow membrane time constant $\left(\tau_{\mathrm{m}}: 48.5 \pm 3.5 \mathrm{~ms}\right)$ in response to hyperpolarizing current injections in current-clamp mode, strong current-voltage rectification, elicitation of a single action potential at the onset of long $(500 \mathrm{~ms})$ (Fig. $1 \mathrm{~A}$ ) depolarizing current steps, and broadening of action potentials during repetitive intracellular stimulation with short ( $1 \mathrm{~ms}$ ) current injection (for an example, see Fig. 6C) (Geiger and Jonas, 2000; Bischofberger et al., 2006b). In addition, control experiments revealed the parent granule cell body and proximal dendrites after biocytin filling from the axon terminal $(n=5)$ (an example is illustrated in Fig. $1 A$ ). GABAergic neurons were identified based on electrophysiological, anatomical, and immunocytochemical criteria (see Results).

Once a stable, simultaneous paired recording was obtained, action potentials were evoked in MF terminals using depolarizing current pulses [ $800 \mathrm{pA}, 1 \mathrm{~ms}, 5$ or 50 pulses at $50 \mathrm{~Hz}$ (these stimulation protocols were used to simulate in vivo conditions of GC burst firing [Henze et al., 2002]); stimulus interval was $\geq 5 \mathrm{~s}$ for 5 action potential protocols, and $\geq 80$ s for 50 action potential protocols], and the postsynaptic GABAergic cell was voltage-clamped at $-70 \mathrm{mV}$. During pair recordings, some GABAergic cells were tested for MF inputs with multiple (up to four), sequentially patched MF boutons. The MF-evoked monosynaptic EPSCs were highly sensitive to the AMPA/kainate receptor antagonist, NBQX [(2,3dioxo-6-nitro-1,2,3,4-tetrahydrobenzo[f]quinoxaline-7-sulfonamide) 5 $\mu \mathrm{M}$ ] (supplemental Fig. $1 A$, available at www.jneurosci.org as supplemental material). The whole-bouton recording technique did not appear to significantly alter synaptic transmission, as control experiments revealed that consecutive bouton-attached and whole-bouton recordings displayed similar postsynaptic responses ( $n=5$ pairs) (supplemental Fig. $1 B, C$, available at www.jneurosci.org as supplemental material). Specifically, after establishing whole-cell recordings from a GABAergic cell, boutons were patched in cell-attached (bouton-attached) mode. In bouton-attached mode (tight seal, access resistance $>1.5 \mathrm{G} \Omega$ ), MF action potentials were evoked (stimuli: $75 \mathrm{mV}, 0.8 \mathrm{~ms}$ ) and monitored (with on-line leak subtraction), aided by the high local density of sodium channels (Engel and Jonas, 2005). After recording the properties of MFEPSCs in bouton-attached mode, the membranes of MF terminals were ruptured and presynaptic action potentials were evoked in wholebouton mode. The properties of MF-GABAergic cell connections were unchanged between the two recording configurations, indicating that intracellular recording does not alter the properties of MF-EPSCs in GABAergic cells. As a control, we also performed paired recordings from MFs and CA3 pyramidal cells (MF: bouton-attached mode, followed by break-in to whole-bouton mode; CA3 pyramidal cell: whole-cell mode). In agreement with previous studies using alternative methods (Jonas et al., 1993; Toth et al., 2000; Lawrence et al., 2004), the MF-evoked monosynaptic EPSCs in the CA3 pyramidal cells showed large unitary amplitudes, high initial transmission probability, and strong facilitation during repeated MF activation (supplemental Fig. 2, available at www.jneurosci.org as supplemental material).

Effective unitary amplitudes of EPSCs (euEPSCs; averages of successful events and failures) elicited by single spikes in MFs were measured from 15 to 40 traces from each experiment, as the difference between the peak of the monosynaptic response and the baseline. Synaptic events were regarded as evoked by the recorded MF terminal if the probability of events was at least 4 times higher than would have been expected from spontaneous events (Fig. 1C,D) (for an example, see supplemental Fig. 3, available at www.jneurosci.org as supplemental material). Spontaneous synaptic events were collected from an equal number of cells from each cell type (regardless of whether or not they were connected to the simultaneously recorded MFs). As expected (Miles, 1990; Mori et al., 2004,
2007), we also detected polysynaptic events after the stimulation of single MFs with various onset delays $(2.1-7.6 \mathrm{~ms})$ and probabilities (range: $11-75 \%)$ ( $n=11$, Fig. $1 C$, gray bars) (note that the criterion for polysynaptic events to be regarded as evoked by the recorded MF was derived from the criterion for monosynaptic events described in this paragraph, above; i.e., the probability of events had to be at least 4 times higher than would have been expected from spontaneous events (see supplemental Fig. 3, available at www.jneurosci.org as supplemental material). Values are mean and SEM, and $n$ is the number of cells or pairs. For statistics, the following tests were used: Mann-Whitney $U$ test, Wilcoxon test, Pearson's $\chi^{2}$ test, Fisher exact test, Student's $t$ test (as indicated in the text). Significant differences were at the level of $p<0.05$, and individual $p$ values are indicated in Results.

Anatomical analysis. To sample the frequency of connections in a cell type-specific manner, every GABAergic cell in or near the stratum lucidum (the termination zone of MFs) that was simultaneously recorded with MF terminals was processed for post hoc identification, regardless of whether or not the pair was monosynaptically connected. After simultaneous pair recordings of MF boutons and CA3 GABAergic neurons, the slices were fixed in $0.1 \mathrm{M}$ phosphate buffer containing $4 \%$ paraformaldehyde and $0.1 \%$ picric acid for $2 \mathrm{~d}$ at $4^{\circ} \mathrm{C}$. After fixation, slices were resectioned at $60 \mu \mathrm{m}$. For immunohistochemistry, sections were incubated with two of the following primary antibodies raised against parvalbumin (PV) (Swant PV28; 1:1000, polyclonal rabbit), cholecystokinin (CCK) (Dr. G. Ohning, CURE/Digestive Diseases Research Center, Antibody/RIA Core, Los Angeles, CA; 1:1500, polyclonal mouse), somatostatin (SOM) (Millipore Bioscience Research Reagents; MAB354; 1:500, monoclonal rat, YC7), neuropeptide Y (NPY) (DiaSorin 208001; 1:1000, polyclonal rabbit) (note that the PV and NPY antibodies were never incubated together) overnight in $0.5 \%$ Triton X-100 and $2 \%$ normal goat serum containing TBS buffer at $4^{\circ} \mathrm{C}$. Immunoreactions were revealed using appropriate Alexa 488- or Alexa 594-conjugated secondary goat antibodies against rabbit, mouse, and rat, and biocytin staining was revealed using Alexa 350-conjugated streptavidin. After checking the immunoreactions of the recorded GABAergic cells, sections were further processed to reveal the fine details of the morphology of the cells using a conventional diaminobenzidine (DAB) staining method. Briefly, after washing in phosphate buffer, endogenous peroxidase activity was blocked with $1 \% \mathrm{H}_{2} \mathrm{O}_{2}$. After another wash, sections were incubated with $\mathrm{ABC}$ (avidin-biotin complex) reagent (Vectastain ABC kit, Vector Laboratories) in $0.1 \%$ Triton X-100 containing buffer for $1 \mathrm{~h}$ at room temperature. The reaction was developed with $\mathrm{DAB}$ and $\mathrm{NiCl}_{2}$ for $8-15 \mathrm{~min}$ and stopped with $\mathrm{H}_{2} \mathrm{O}_{2}$ solution. Sections were dehydrated (50, 70, 90, and 95\%, absolute ethanol and CitriSolv solutions) on slides and mounted using DPX mounting media (Electron Microscopy Sciences). In those experiments in which MF boutons were also labeled with biocytin $(n=5)$ (Fig. $1 A$ ), slices were processed without resectioning for DAB staining only, and were subjected to $15 \mathrm{~min}$ of 50,75 , and $50 \%$ ethanol treatments before the $\mathrm{ABC}$ reaction. Cells were visualized with epifluorescence or conventional transmitted light microscopy (Zeiss, Axioskop 2). The axonal arbors of cells were drawn using a camera lucida from one representative section only (usually from the section in which the soma of the cell was located) using a $100 \times$ objective. The dendrites were reconstructed from multiple sections with a $60 \times$ objective.

\section{Results \\ Diverse GABAergic cells are targeted by mossy fibers}

Overview

During the MF-GABAergic cell paired recordings, GABAergic cells were tested for MF inputs with up to four sequentially patched MF boutons (see Materials and Methods). Specifically, 170 cells were tested with one MF bouton, 48 with two, 4 with three, and 1 with four MF boutons, resulting in a total of 282 pairs (note that $1 \times 170+2 \times 48+3 \times 4+4 \times 1=282$ ). Of 282 simultaneous MF-GABAergic cell recordings, monosynaptic connections (latency range: $0.4-1.1 \mathrm{~ms}$ ) (Fig. 1C, black bars, $D$ ) were present in 29 pairs $(10.3 \%)$. 
The paired recordings revealed that MFs contacted a hitherto unrecognized diversity of GABAergic cell types. Four distinct GABAergic cell types received monosynaptic MF inputs: the fast-spiking basket cells (FSBCs), the regular-spiking basket cells (RSBCs), the ivy cells (IvyCs), and the spiny lucidum cells (SLCs). In addition, we found one monosynaptic MF connection among non-ivy, dendrite-targeting cells (DTCs). In contrast, MF-associated cells (MFAs) were not observed to receive monosynaptic MF inputs. The total number of identified cells in MF pair recordings was 126, including 12 FSBCs +24 RSBCs + 19 IvyCs +37 SLCs + 23 MFAs +11 DTCs. Because some GABAergic cells were pair recorded with more than one MF, the number of pairs tested ( $n=$ 164) was higher than the number of identified cells in MF pair recordings $(n=126)$ (see previous sentence), and included 14 FSBCs + 29 RSBCs + 30 IvyCs + 46 SLCs +30 MFAs + 15 DTCs. Additionally, 97 cells (of 118 pairs) that were tested for MF inputs with at least one simultaneously recorded MF terminal could not be identified. Note that 164 (the number of pairs with identified postsynaptic cells) +118 (the number of pairs without identified postsynaptic cells) $=282$ (the total number of recorded pairs).

Specific description of cell types

MFs evoked monosynaptic EPSCs in both types of nonoverlapping, perisomatically projecting basket cells, the FSBCs and RS$\mathrm{BCs}$, indicating that granule cells can directly regulate the distinct time-keeping and modulatory functions of these two BC classes (Freund and Katona, 2007). FSBCs (Fig. 2) were classified based on their characteristic axons (forming the basis of classifying these cells as BCs) and firing properties (allowing these cells to be specifically classified as FSBCs). For all FSBCs, the majority of the axons were located in the CA3 stratum pyramidale. In addition, all FSBCs showed characteristic, high-frequency, nonaccommodating firing (Fig. $2 A$, inset; supplemental Fig. $4 A$, available at www. jneurosci.org as supplemental material) with fast action potentials (half-width: $0.52 \pm 0.07 \mathrm{~ms}$ ) (supplemental Fig. $4 B$, available at www.jneurosci.org as supplemental material) and large-amplitude $(16.7 \pm 1.7 \mathrm{mV}$; measured between the threshold of action potential and the peak hyperpolarization), narrow (half-width: $12.05 \pm 1.59 \mathrm{~ms}$ ) afterhyperpolarization (AHP) (supplemental Fig. 4C, available at www.jneurosci.org as supplemental material). Furthermore, in contrast to SLCs,

\section{Fast-spiking basket cell}
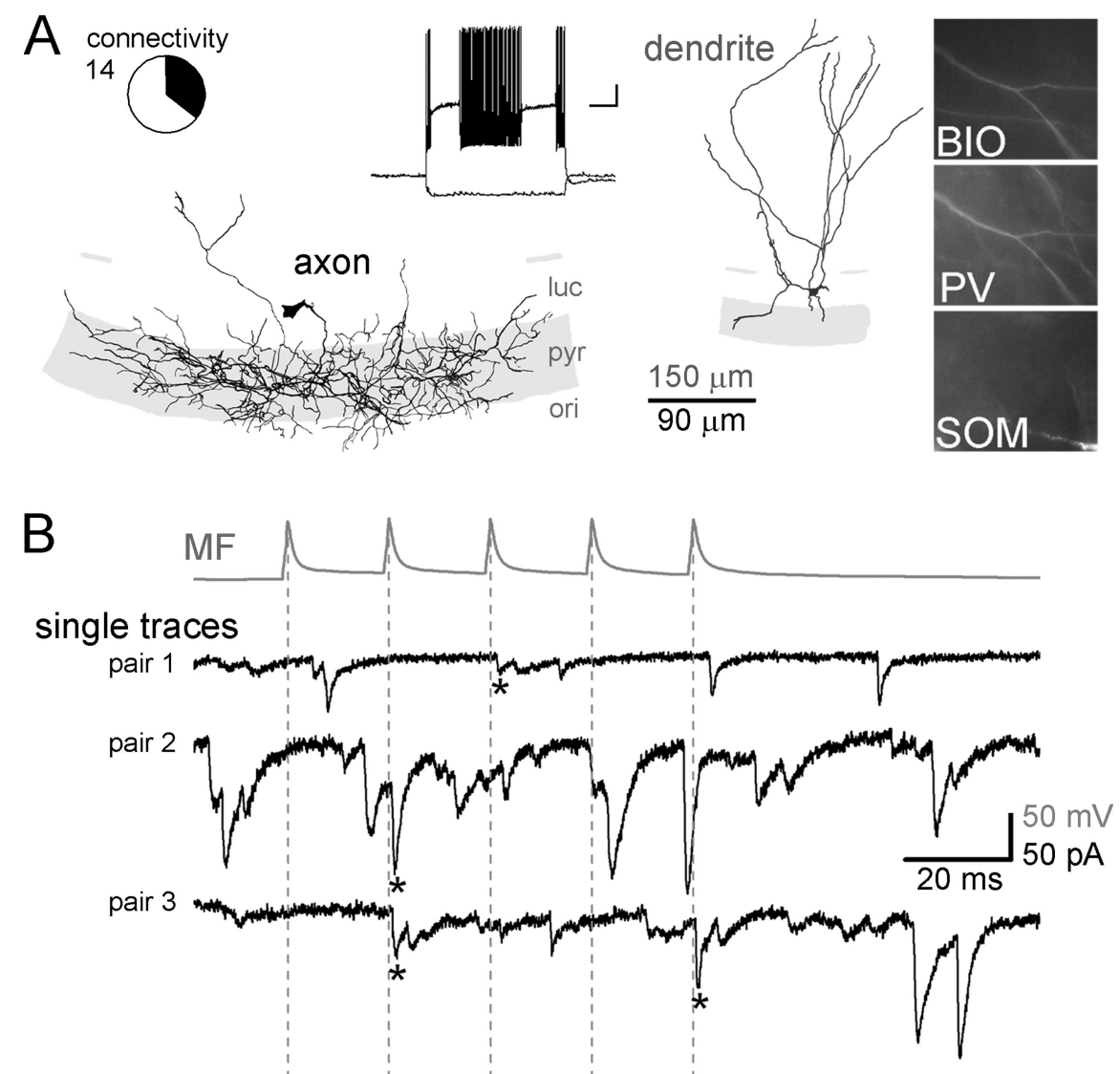

average ( $\mathrm{n}=5$ pairs)
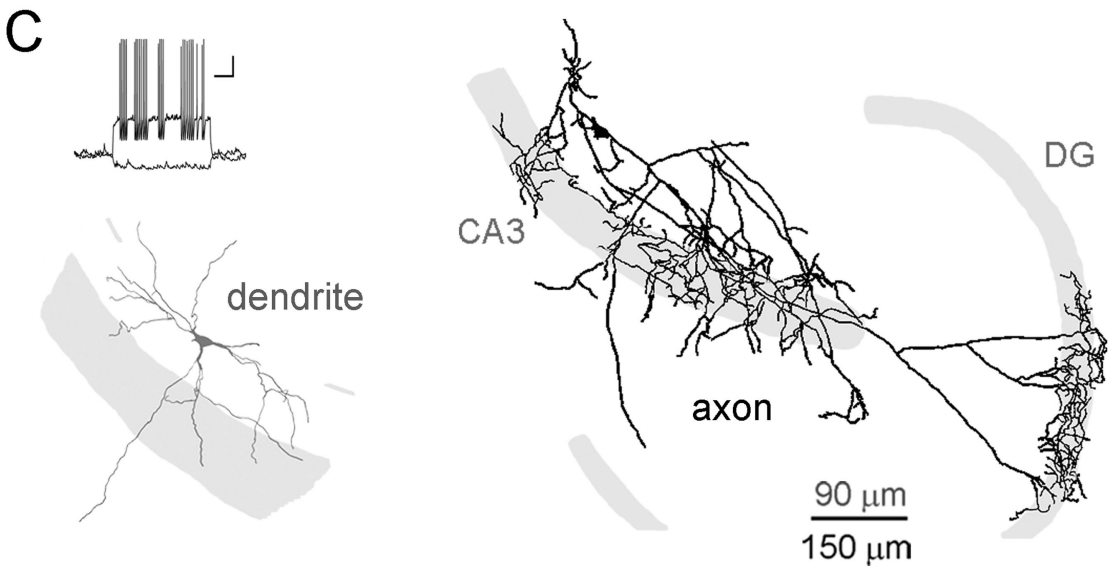

Figure 2. MFs are monosynaptically connected to FSBCs in CA3. $\boldsymbol{A}$, Dendritic (gray) and axonal (black) arborizations, firing pattern, and immunoreactivities of a representative FSBC that received monosynaptic MF inputs. Circle graph indicates the relative proportion of the FSBCs (shaded black in the circle graph) that received monosynaptic inputs from MFs of the $14 \mathrm{MF}-\mathrm{FSBC}$ pairs (BI0, biocytin; ori, stratum oriens; pyr, stratum pyramidale; luc, stratum lucidum) (calibration for the firing pattern: $20 \mathrm{mV}$, $200 \mathrm{~ms})$. $\boldsymbol{B}$, Top (gray), Average action potential trace from a MF ( 5 action potentials at $50 \mathrm{~Hz}$ ) that was connected to a FSBC. Middle traces (black), Representative single postsynaptic responses to presynaptic MF stimulation, and spontaneous events, from three FSBCs (note that the camera lucida drawing of the FSBC from which the recording labeled "pair 1" was obtained is illustrated in $A$ ). Dashed lines indicate the peak of presynaptic action potentials and asterisks mark monosynaptic events in FSBCs. Bottom (black), Average MF-evoked responses from all FSBCs monosynaptically connected to MFs (specifically, the average of the average responses from all five connected pairs is shown). Note the high number of spontaneous events on the single traces (see also Fig. 70 ). C, An example FSBC in the CA3 that received MF-EPSC and had significant axonal innervations of the DG granule cell layer (black, axon; gray, dendrite). 


\section{Regular-spiking basket cell}

A connectivity
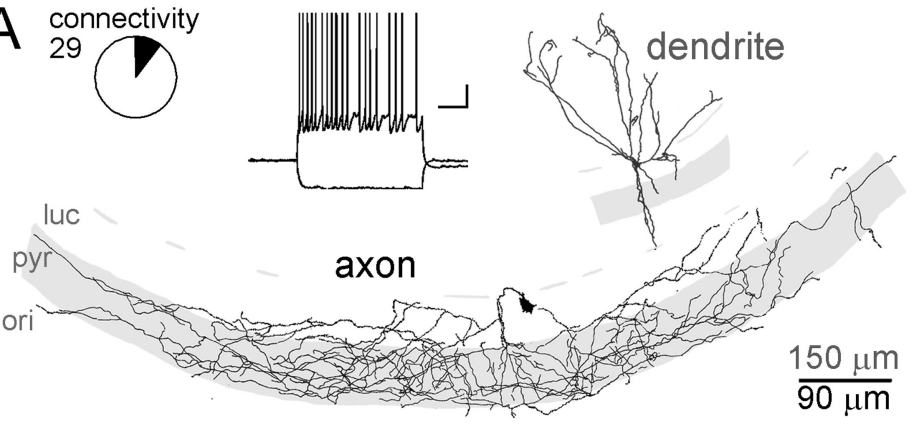

B

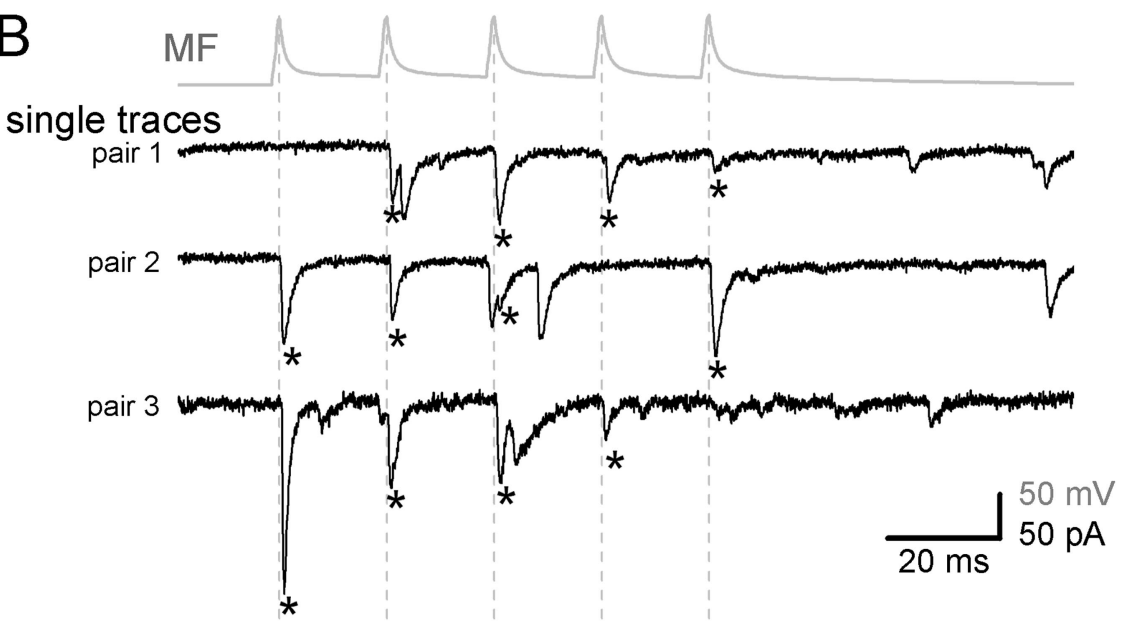

average ( $\mathrm{n}=3$ pairs)

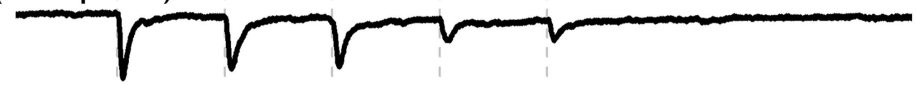

Figure 3. MFs are monosynaptically connected to RSBCs in CA3. A, Dendritic (gray) and axonal (black) arborizations, firing pattern, and immunoreactivities of a representative RSBC that received monosynaptic MF inputs. Circle graph indicates the relative proportion of the RSBCS (shaded black in the circle graph) that were monosynaptically connected to presynaptic MFs from the 29 tested MF-RSBC pairs (BI0, biocytin; ori, stratum oriens; pyr, stratum pyramidale; luc, stratum lucidum) (calibration for the firing pattern: $20 \mathrm{mV}, 200 \mathrm{~ms}$ ). $\boldsymbol{B}$, Top (gray), Average action potential trace from a MF that was connected to a RSBC. Middle traces (black), Representative single traces from each of the three postsynaptically coupled RSBCs (note that the postsynaptic cell from which the trace labeled "pair 3" was obtained is shown in A). Bottom (black), Average MF-evoked responses in all RSBCs that received monosynaptic inputs from MFs (the average of the average responses from all three connected pairs is shown). Dashed lines indicate the peak of presynaptic action potentials, and asterisks mark monosynaptic events in RSBCs. Note the relatively low frequency of spontaneous events.

DTCs, and MFAs, FSBCs showed low-input resistance (143 \pm 17 $\mathrm{M} \Omega$; measured at the peak hyperpolarization in response to $-100 \mathrm{pA}$ current injection), fast membrane time constant $\left(\tau_{\mathrm{m}}=\right.$ $14.5 \pm 1.6 \mathrm{~ms}$; single exponential fit), and no prominent sag. PV immunopositivity was found in all tested cells (6 of 6 tested), often revealed predominantly in the dendrites (Fig. $2 \mathrm{~A}$ ) (note that partial wash-out of the antigen during long recordings may have contributed to the frequently low levels of PV immunoreactivity in the soma). CCK and SOM immunopositivity was not detected ( 0 of 3 and 0 of 7 , respectively) in FSBCs. Altogether, $n=$ 12 identified FSBCs were in our database from 14 MF-FSBC pairs (the difference between 12 and 14 is a result of the cells that were pair recorded with $>1$ MF terminal), and $n=5$ MF-FSBC pairs were monosynaptically connected (Fig. $2 B$ ).

Interestingly, although FSBCs are typically thought of as an interneuron type with predominantly local (in this case, within
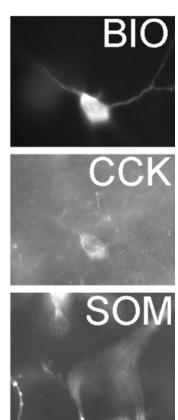

CA3) axon collaterals, three CA3 FSBCs had significant axonal projections in the granule cell layer of the DG, in addition to the dense innervation of the stratum pyramidale of the CA3 $(n=3)$ (Fig. $2 C$ ). Of these three DG-projecting FSBCs, two were monosynaptically innervated by MFs, suggesting that individual FSBCs may have dual functional roles by being involved in both MF-modulated feedforward inhibition within the CA3 and MFinduced feedback inhibition of the DG.

RSBCs (Fig. 3) are thought to play complementary roles to FSBCs, because of their different input and output properties (Hefft and Jonas, 2005; Földy et al., 2006; Glickfeld and Scanziani, 2006), regulation by modulatory systems (Földy et al., 2007; Freund and Katona, 2007; Neu et al., 2007) and in vivo firing properties (Klausberger et al., 2005). In our sample, all RSBCs had the majority of their axons arborizing in the pyramidal cell layer of CA3 (24 of 24; all cells), forming large, closely placed boutons. In sharp contrast to FSBCs, the firing of RSBCs (Fig. 3A, inset) showed characteristic adaptation with slower action potentials (half-width: $0.76 \pm 0.07$ ms) (supplemental Fig. $4 B$, available at www.jneurosci.org as supplemental material), and small-amplitude (12.9 \pm 0.7 $\mathrm{mV}$ ) and wide AHPs (half-width: $59.4 \pm$ $17.7 \mathrm{~ms}$ ) (supplemental Fig. 4C, available at www.jneurosci.org as supplemental material). All of the tested RSBCs were positive for CCK (Fig. 3A; 21 of 21 tested cells) but were negative for SOM and PV ( 0 of 20,0 of 2, respectively). In contrast to the CCK+ MFAs (see Fig. 6; see below), none of the CA3 RSBCs sent axon collaterals to the hilus. Altogether, there were 24 RSBCs from $29 \mathrm{MF}-\mathrm{RSBC}$ pairs (the difference between 24 and 29 is the result of the cells that were pair recorded with $>1 \mathrm{MF}$ bouton), and $n=3 \mathrm{MF}-\mathrm{RSBC}$ pairs were monosynaptically connected (Fig. 3B).

In addition to perisomatically projecting GABAergic cells, MFs provided monosynaptic excitation to dendritically projecting inhibitory cells, specifically, to the recently described IvyCs (Fig. 4) (Fuentealba et al., 2008). IvyCs belong to the family of neurogliaform cells that are known to provide powerful, long-lasting inhibition to postsynaptic cells through their extremely dense axonal cloud (Tamás et al., 2003; Price et al., 2005; Szabadics et al., 2007). However, in contrast to hippocampal neurogliaform cells (Price et al., 2005), IvyCs release GABA onto the proximal dendritic region of pyramidal cells as they innervate the inner portion of stratum radiatum and stratum oriens (Fuentealba et al., 2008). The most characteristic property of IvyCs was their dense axonal arborization in strata radiatum and oriens forming small and frequent boutons (all IvyCs showed the latter property) (supplemental Fig. 5A, C, D, available at www.jneurosci.org as supplemental material) (note that the present data comprise the first description of IvyCs out- 
side of the CA1 region). Ivy cells expressed NPYs ( 3 of 3 tested cells) but not SOMs $(0$ of 10$)$, CCKs (0 of 10), and PVs (0 of 4 ) (Fuentealba et al., 2008). IvyCs, similar to neurogliaform cells, but in contrast to the other cell types in this study, were characteristically late-spiking cells (Fig. 4A, inset) (Kawaguchi and Kubota, 1997), and they elicited action potentials with large $(17.5 \pm 0.8 \mathrm{mV})$ and wide $(89 \pm 12.5 \mathrm{~ms})$ AHPs. Altogether, there were $n=19$ IvyCs of 30 tested MF-IvyC pairs (the difference between 19 and 30 is a result of the cells that were tested with $>1$ MF bouton during pair recordings), and $n=5 \mathrm{MF}-\mathrm{IvyC}$ pairs were monosynaptically connected (Fig. $4 B$ ).

In addition to IvyCs, MFs also evoked monosynaptic EPSCs in a single non-IvyC, DTC. DTCs in this study indicate a loose cell group that we so named (only for the purposes of the current study) because they shared one common property, namely, they all innervated the strata radiatum and/or oriens, but they were clearly heterogeneous in some other cellular properties. Specifically, DTCs were distinguished from IvyCs based on their large, infrequent boutons, and non-latespiking firing pattern (for details, see supplemental Fig. 5, available at www.jneurosci.org as supplemental material). However, DTCs showed heterogeneity in terms of their immunohistochemical markers, with some of them being positive for SOM ( 1 of 4 tested), whereas others expressed CCK (2 of 5 tested). Furthermore, the passive and active membrane properties of DTCs also showed variability, including the presence or absence of sag, accommodating or nonaccommodating firing, and shape of AHPs (data not shown). Altogether, there were $n=11$ DTCs of 15 MF-DTC pairs (the difference between

11 and 15 is the result of the cells that were tested with $>1 \mathrm{MF}$ boutons during the pair recordings). Due to the rarity of MF inputs to DTCs ( $n=1$ monosynaptic pair of 15 pairs) and the apparent heterogeneity within this group of cells, these cells were not further considered in the rest of the study.

In addition to GABAergic cell types whose primary axonal targets are within the CA3, we found monosynaptic MF inputs to SLCs (Fig. 5). SLCs are GABAergic cells that project mainly to the medial septum and possess relatively few local axon collaterals near the cell body (Gulyás et al., 1992; Jinno et al., 2007; Takács et al., 2008). One of the main characteristics of SLCs is that, in contrast to other GABAergic cells in this study, the primary dendrites of SLCs are aligned with and largely restricted to stratum lucidum (and, to a lesser extent, pyramidale), and the dendrites are densely covered with large numbers of dendritic spines (Fig. $5 A$ ) (all SLCs showed the characteristic dendritic orientation and the dense spines). As expected from neurons with septal projections, in most cases the main axon of SLCs coursed toward the fimbria-fornix and appeared severed on the surface of the slice (Fig. 2A, asterisk). Like most other projecting GABAergic cell types (Jinno et al., 2007), the vast majority of SLCs were positive for SOM (24 of 26 tested SLCs) and for NPY (7 of 7), but not for CCK ( 0 of 17) and PV (0 of 6). Note that we were not able to reliably test for the presence of calretinin, which is another marker for SLCs, most likely because of wash-out of intracellular constituents from postsynaptic cells during the long-lasting somatic recordings. In response to hyperpolarizing current injections, SLCs responded with a prominent sag $(18.5 \pm 2.8 \%)$ (measured as the relative difference between the peak hyperpolarization and steady-state hyperpolarization during a $1 \mathrm{~s}$ long, $100 \mathrm{pA}$ current pulse), and the input resistance $(253 \pm 22$ $\mathrm{M} \Omega$ ) and membrane time constant $\left(\tau_{\mathrm{m}}=32.4 \pm 2.7 \mathrm{~ms}\right)$ were the largest among the studied cells. Altogether, there were $n=37$ SLCs in our data base from the total of 46 MF-SLC pairs (the difference between 37 and 46 is a result of the SLCs that were pair recorded with $>1 \mathrm{MFs}$ ), and $n=15 \mathrm{MF}$-SLC pairs were monosynaptically connected (Fig. $5 B$ ). Note that in SLCs the existence of monosynaptic MF inputs was often revealed only after $>10$ presynaptic action potentials at $50 \mathrm{~Hz}$ (Fig. $5 C_{1-3}$; for details see below). Interestingly, $n=4$ SLCs (two of which were monosyn- 

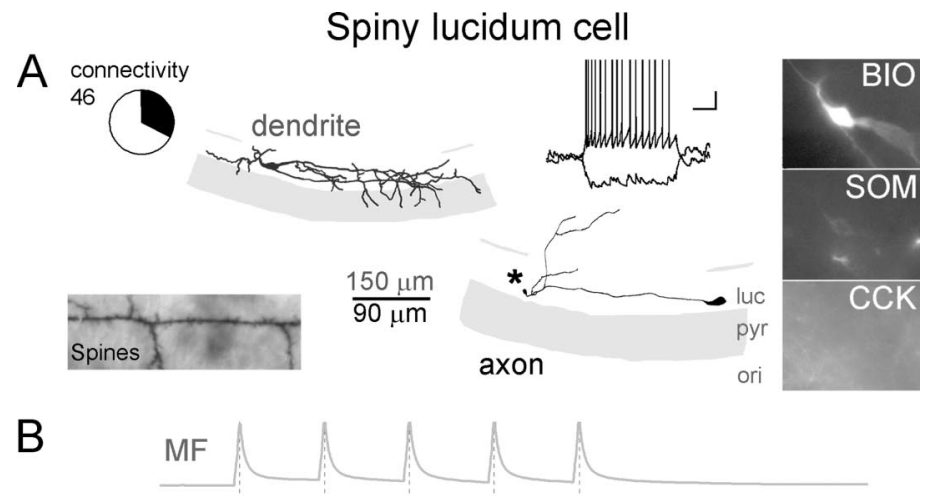

single traces
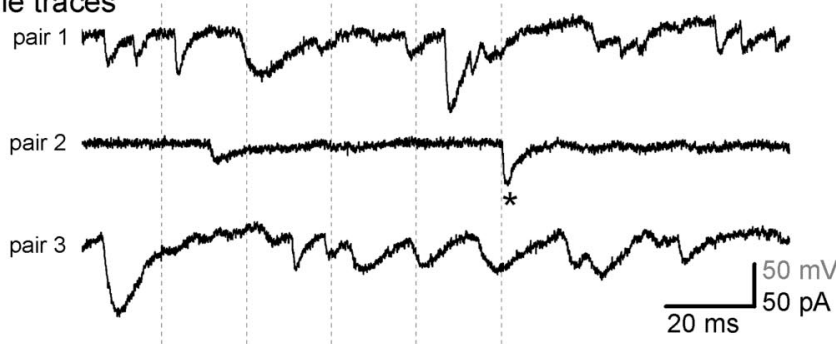

average $(n=15$ pairs $)$

$\mathrm{C}_{1}$
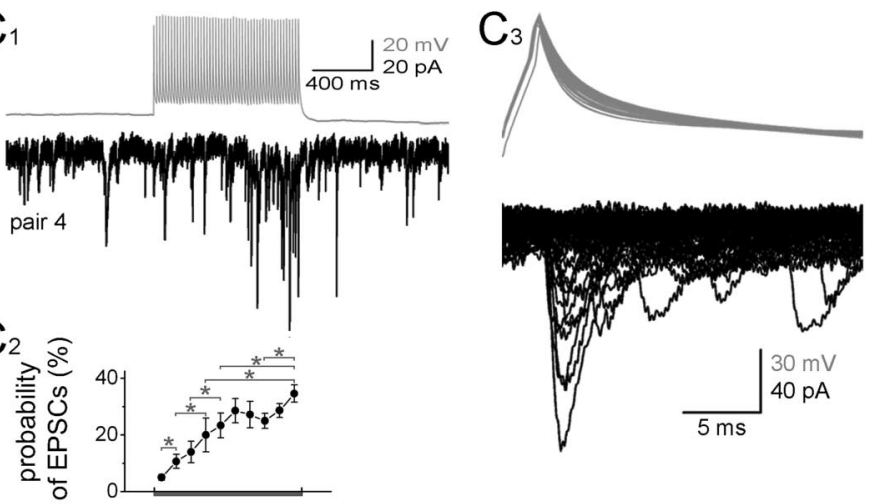

D

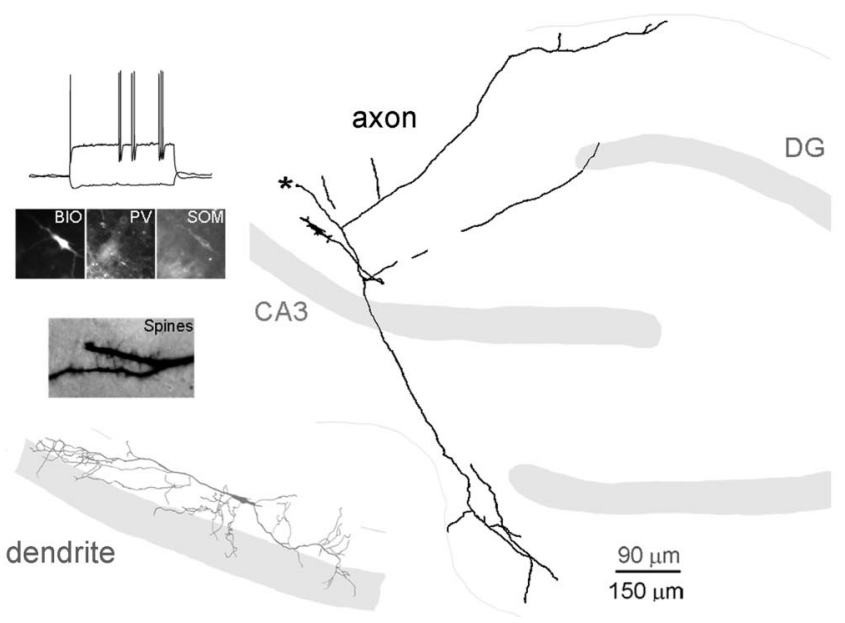

Figure 5. MFs are monosynaptically connected to SLCs in CA3. A, Dendritic (gray) and axonal (black) arborizations, firing pattern, the spiny dendritic surface, and immunoreactivities of a representative SLC that received monosynaptic MF inputs. Note that the SLC dendrites aligned with the stratum lucidum. Asterisk marks the severed main (presumably long distance-projecting) axon of the SLC on the surface of the slice. Circle graph indicates the relative proportion of the SLCS (shaded black in the circle graph) that received monosynaptic input from MFs of the 46 MF-SLC pairs (BI0, biocytin; ori, stratum oriens; pyr, stratum pyramidale; luc, stratum lucidum) (calibration for the firing pattern: $20 \mathrm{mV}, 200 \mathrm{~ms})$. $\boldsymbol{B}$, Top (gray), Average action potential trace from a MF that was monosynaptically connected to a SLC. Middle traces (black), Representative single traces from three SLCs that received monosynaptic inputs from MFs. Bottom (black), Average MFevoked responses from all SLCs that received monosynaptic MF inputs (see $\boldsymbol{C}$ (the average of the average responses from all 15 connected aptically connected to the pair-recorded MFs) also showed back-projection to the DG (Fig. 5D).

In contrast to the previously described cell types, MFAs were never observed to receive monosynaptic MF inputs (Fig. 6). MFAs are found exclusively in the CA3 area and innervate specifically the stratum lucidum of CA3 (hence the name of the cell type) and the hilus (Vida and Frotscher, 2000; Losonczy et al., 2004) (note that it is the axons, and not the dendrites, that align with the MF termination zone). In agreement with previous studies, most of the axons of identified MFAs within the CA3 in our sample are located in the stratum lucidum, running parallel with the pyramidal cell layer (all MFAs had axons showing the latter property), and also send collaterals to the hilus ( 19 of 23 cells). Furthermore, the majority of tested MFAs were positive for CCK (11 of 14 cells), but PV and SOM expressions were never observed ( 0 of 3 , and 0 of 8 , respectively). In contrast to RSBCs, MFAs responded with a significant sag (15.3 \pm $3.7 \%$; measured as the relative difference between the peak hyperpolarization and steady-state hyperpolarization during a 1-s-long, $100 \mathrm{pA}$ current pulse) to hyperpolarizing current injections. MFAs showed an adapting firing pattern (Fig. 6, inset) with small-amplitude AHPs (10.8 \pm $0.6 \mathrm{mV}$ ) (supplemental Fig. $4 C$, available at www.jneurosci.org as supplemental material). Altogether, there were 23 MFAs of 30 MF-MFA tested pairs (the difference between 23 and 30 is the result of MFAs that were tested with $>1$ MF bouton during the pair recordings), with none of the MF-MFA pairs exhibiting monosynaptic connections (note that all connections to

\footnotetext{
$\leftarrow$

pairs is shown). Dashed lines indicate the peak of presynaptic action potentials and asterisks mark monosynaptic events in SLCs. Note the relatively frequent spontaneous events on the single traces. C, Synaptic connections from MFs could be observed in SLCs, mostly only during long trains of presynaptic stimulation because of low initial transmission probabilities. $C_{1}$, Postsynaptic trace in a SLC in response to stimulation of presynaptic MF with 50 action potentials at $50 \mathrm{~Hz}$. $\mathrm{C}_{2}$, Probability of monosynaptic EPSCs in SLCS $(n=15)$ during long presynaptic MF trains (plot aligned with presynaptic action potentials on the top in $\boldsymbol{C}_{\boldsymbol{p}}$; same frequency and number of action potentials as in sample trace). Asterisks mark significant differences (paired Wilcoxon test; $p<0.05$ or smaller). $\boldsymbol{C}_{3}$, Superimposed presynaptic action potentials (top) and postsynaptic responses (bottom). Note the change in the width of the action potentials characteristic for MFs and the variability of the amplitude of the evoked events. $D$, An example SLC that projected from the CA3 to the DG. Note that the main axon exited the surface of the slice (asterisk).
} 
MFAs were tested with long, highfrequency trains of presynaptic stimuli consisting of 50 action potentials at $50 \mathrm{~Hz}$, and, in many cases, even longer trains and higher frequencies were used, up to 200 action potentials and $120 \mathrm{~Hz}$ ).

Altogether, these data demonstrate that MFs contact several distinct types of GABAergic neurons within the CA3 network, including both perisomatically and dendritically projecting neurons and cells with various extrahippocampal projections (Figs. 2C, 5D).

\section{Target selectivity}

The results described above demonstrate that MFs directly excite a diverse GABAergic system with spatially distinct projection patterns both within and outside the CA3. However, our data also show that the probability of finding monosynaptic MFGABAergic cell pairs varied according to cell type, suggesting that the probabilities of monosynaptic MF innervations are postsynaptic cell type specific (Fig. 7A). Monosynaptic MF-EPSCs were found with high probability if the recorded GABAergic cells were perisomatically innervating FSBCs $(n=5$ monosynaptically connected pairs of 14 tested pairs, 35.7\%) and septum-projecting SLCs $(n=15$ connected of $46 \mathrm{MF}-\mathrm{SLC}$ pairs, $32.6 \%$ ). In contrast, IvyCs and RSBCs were less likely to be functionally connected to simultaneously recorded MFs ( $n=5$ monosynaptic pairs of $30 \mathrm{MF}-\mathrm{IvyC}$ pairs, $16.7 \% ; n=3$ monosynaptic pairs of $29 \mathrm{MF}-\mathrm{RSBC}$ pairs, $10.3 \%)$. The most striking difference in this regard was exhibited by the MFAs (Vida and Frotscher, 2000; Losonczy et al., 2004) that were never observed to receive monosynaptic EPSCs from MFs $(n=0$ connection of 30 MF-MFA pairs). Statistical analyses (Pearson's $\chi^{2}$ test) of the probability of connections between identified CA3 GABAergic cells and nearby MF terminals indicated significant differences among the cell types $\left(\chi^{2}=16.8 ; p=\right.$ $0.0021)$. Furthermore, residuals from the $\underline{\chi^{2} \text { test }}(($ observed - expected $) / \sqrt{(\text { ex- }}$ pected $)$ suggest that the MF innervation probability of FSBCs and SLCs are different from that of RSBCs, IvyCs, and MFAs $(1.46,2.16$ vs $-1.05,-0.27$, and -2.37 , respectively). Indeed, paired statistical comparison (Fisher's exact test) of the MF connection probabilities in GABAergic cell types (i.e., two cell types were compared at a time) indicated that MFAs are significantly less likely to be innervated by MFs compared with every other cell (Fig. $7 A ; \chi^{2}=15.4,4.8,18.1$, and 7.95 for MFAs compared with FSBCs, RSBCs, SLCs, and IvyCs, respectively; $p=$ $0.00008, p=0.029, p=0.00002$, and $p=0.048$, respectively).

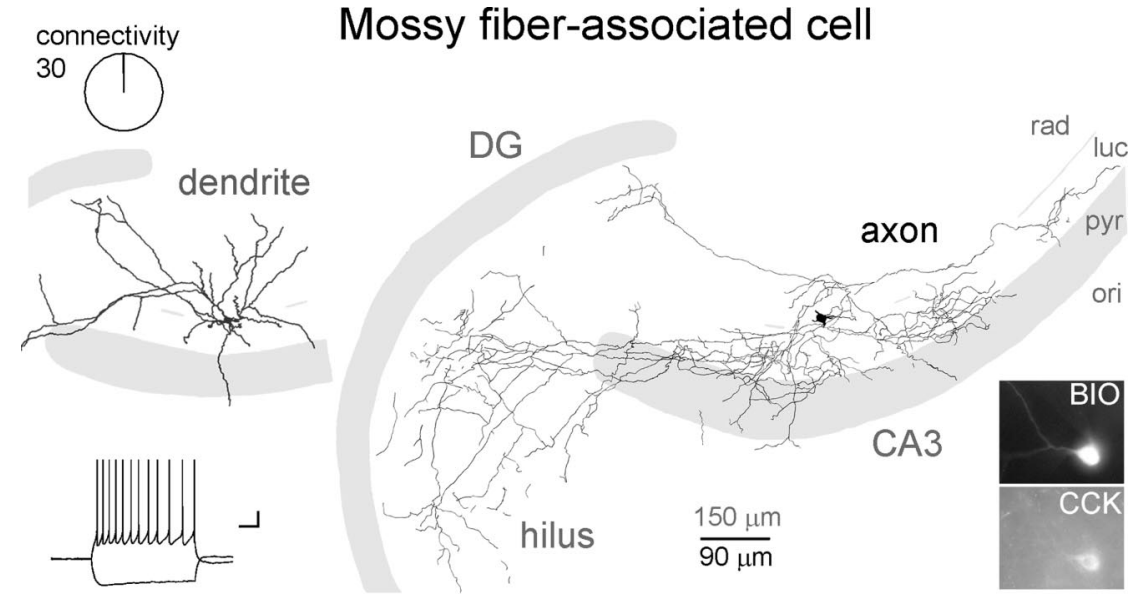

Figure 6. CA3-specific MFAs were not found to be monosynaptically innervated by MFs. Dendritic (gray) and axonal (black) arborizations, firing pattern, and immunoreactivities of a representative MFA (abbreviations same as in Fig. $3 A$ ). Note that the majority of the axons are located in the stratum lucidum and in the hilus, and also that the dendrites are not aligned with the mossy fiber pathway.

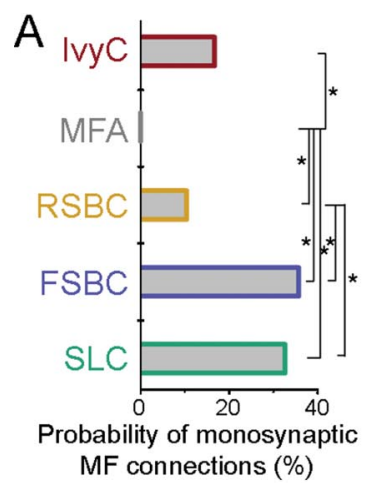

$\mathrm{D}$

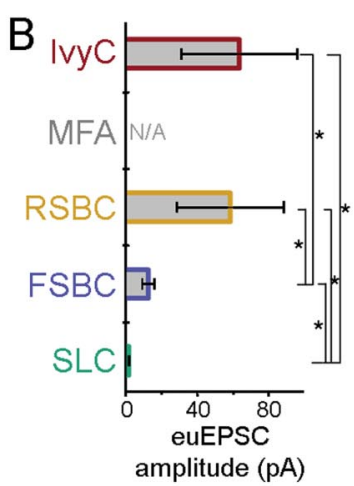

amplitude $(\mathrm{pA})$

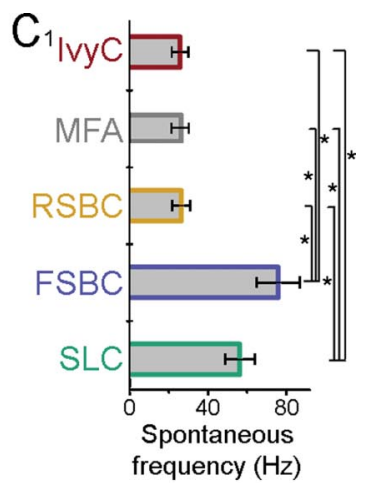

$\mathrm{C}_{2}$

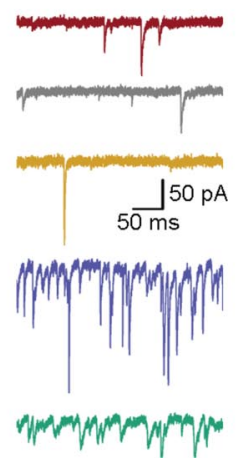

Figure 7. Cell type-specific correlations between the anatomical and physiological properties of MF inputs to CA3 GABAergic cells. $\boldsymbol{A}$, Percentage of monosynaptically connected MF-GABAergic cell pairs (asterisks mark significant differences, Fisher exact test; for $p$ values, see Results) (color code applies through $\boldsymbol{A}-\boldsymbol{D}$ ). $\boldsymbol{B}$, Average amplitudes of euEPSCs (including failures) evoked by the first presynaptic spike from all cells receiving monosynaptic MF inputs ( $n=5,0,3,5$, and 15 , respectively). Asterisks mark significant differences (Mann-Whitney nonparametric $U$ test; for $p$ values, see legend to Table 1). $\boldsymbol{C}_{1}$, Average spontaneous event frequencies in the five different cell types ( $n=11$ from each). Asterisks mark significant differences (Mann-Whitney nonparametric $U$ test; for $p$ values, see Results). $C_{2}$, Example traces illustrating cell type-specific differences in spontaneous event frequencies. $\boldsymbol{D}$, Three-dimensional representation of the relative number and euEPSC amplitude of MF inputs and frequency of spontaneous synaptic events in four different CA3 GABAergic cells (spheres indicate the average values for each cell type; thin lines projecting to zero values are also included for better visualization of the relative positions of the spheres) (blue, FSBC; green, SLC; yellow, RSBC; red, IvyC).

Furthermore, RSBCs are also significantly less likely to be connected to neighboring MFs than FSBCs and SLCs $\left(\chi^{2}=4.0\right.$ and 4.8 , for RSBCs compared with FSBCs and SLCs, respectively; $p=$ 0.045 and $p=0.028$, respectively).

Note that the method of MF contact estimation used here is 
Table 1. Postsynaptic cell type-dependent properties of MF-EPSCs

\begin{tabular}{|c|c|c|c|c|c|c|}
\hline & $\begin{array}{l}\text { Amplitude of successes during } \\
\text { the } 5 \text { AP trains }(\mathrm{pA})^{a}\end{array}$ & $\begin{array}{l}\text { Transmission probability } \\
\text { during } 5 \text { AP trains }(\%)^{b}\end{array}$ & $\begin{array}{l}\text { euEPSC during } 5 \text { AP } \\
\text { trains }(\mathrm{pA})^{c}\end{array}$ & $\begin{array}{l}\text { Transmission probability } \\
\text { for the first AP }(\%)^{d}\end{array}$ & $\begin{array}{l}\text { euEPSC for the } \\
\text { first AP (pA) }\end{array}$ & $\begin{array}{l}\tau \text { decay of EPSCs during } \\
\text { the } 5 \text { AP trains (ms) }\end{array}$ \\
\hline IvyC & $92.5 \pm 24.2$ & $64.4 \pm 16.7$ & $72.5 \pm 29$ & $55.3 \pm 14.1$ & $63.5 \pm 32.5$ & $1.74 \pm 0.29$ \\
\hline RSBC & $73.6 \pm 19.4$ & $57.8 \pm 9.3$ & $49.4 \pm 13.1$ & $43.4 \pm 20.7$ & $58.6 \pm 29.9$ & $2.32 \pm 0.58$ \\
\hline FSBC & $28 \pm 4.4$ & $21.6 \pm 6.6$ & $7.2 \pm 2$ & $22.9 \pm 5.2$ & $12.7 \pm 3.4$ & $2.12 \pm 0.36$ \\
\hline SLC $1-5$ AP (46-50 AP) & N/A $(49.9 \pm 9.3)$ & $5.3 \pm 1.1(34.6 \pm 3.3)$ & $3 \pm 0.8(21.5 \pm 5.7)$ & $2.4 \pm 0.8$ & $1.7 \pm 0.3$ & $\mathrm{~N} / \mathrm{A}(3.54 \pm 0.53)$ \\
\hline
\end{tabular}

N/A, Not applicable.

${ }^{a}$ Amplitude of successes during the first five presynaptic action potentials (APs), excluding failures (significant differences: FSBCs and RSBCs: $p=0.037, \mathrm{FSBC}$ and IvyCs: $p=0.012 ;$ Mann-Whitney nonparametric $U$ test).

${ }^{b}$ Transmission probability during 5 AP trains: Percentage of trials when the first five presynaptic action potentials at $50 \mathrm{~Hz}$ were followed by monosynaptic MF-EPSCs (significant differences: FSBCs and RSBCs: $p=0.037$, RSBCs and SLCs: $p=0.01$, and lvy(s and SLCs: $p=0.0016 ;$ Mann-Whitney test).

'euEPSC amplitudes included both successes and failures (significant differences: for the 1st AP, FSBCs and RSBCs: $p=0.037$, FSBCs and lvyCs: $p=0.037$, FSBCs and SLCs: $p=0.012, \mathrm{RSBC}$ and SLCs: $p=0.014$, and IvyCs and SLCs: $p=$ 0.0027 ; during the 5 AP train, FSBCs and RSBCs: $p=0.037$, FSBCs and lvyCs: $p=0.022$, RSBCs and SLCs: $p=0.012$, and IvyCs and SLCs: $p=0.0019 ;$ Mann-Whitney test). $N$ (number of cells) $=5,3,5$, and 15 for IvyCs, RSBCs, FSBCs, and SLCs, respectively.

${ }^{d}$ Transmission probability for the first AP: Percentage of trials when the first presynaptic action potential was followed by monosynaptic MF-EPSCS (significant differences: FSBCs and SLCs: $p=0.013$, RSBCs and SLCs: $p=0.006$, and IvyCs and SLCs: $p=0.0009 ;$ Mann-Whitney test).

not biased by potential differences in the numerical abundance of the distinct GABAergic cell types in the CA3 network. As indicated above (see Materials and Methods), to determine the distribution of GABAergic cell MF targets, every GABAergic cell that was simultaneously recorded with a nearby MF bouton was identified, regardless of whether or not the pair exhibited synaptic connections. Therefore, this method of estimating MF contacts yielded the relative probability of monosynaptic connections, calculated by dividing the absolute number of monosynaptically connected MF-GABAergic cell pairs for a given cell type by the absolute number of simultaneously recorded (connected and unconnected) MF-GABAergic cell pairs of the same postsynaptic cell type.

It is noteworthy that the relative probabilities of monosynaptic MF connections in distinct types of GABAergic cells remain essentially unchanged if we focus our analysis only on those pairs in which the characteristic immunoreactivity of the pair recorded (including both monosynaptically connected and not connected pairs) GABAergic cells was confirmed (Pearson's $\chi^{2}$ test; $\chi^{2}=$ $18.1 ; p=0.0004)$. Specifically, we found three monosynaptically connected $\mathrm{FSBC}_{(\mathrm{PV}+)^{\mathrm{S}}} \mathrm{s}$ of 8 pair recorded $\mathrm{FSBC}_{(\mathrm{PV}+)} \mathrm{s}(37.5 \%$; compared with $35.7 \%$ for all MF-FSBC pairs; see previous paragraph), 2 monosynaptically connected $\mathrm{RSBC}_{(\mathrm{CCK}+)^{\mathrm{s}}}$ of 26 pair recorded $\mathrm{RSBC}_{(\mathrm{CCK}+)^{\mathrm{s}}} \mathrm{s}(7.7 \%$, compared with $10.3 \%$ for all MFRSBC pairs), and 12 monosynaptically connected $\mathrm{SLC}_{(\mathrm{SOM}+)}$ of 30 pair recorded $\mathrm{SLC}_{(\mathrm{SOM}+)} \mathrm{s}$ (40\%, compared with $32.6 \%$ for all MF-SLC pairs). Note that a similar calculation cannot be meaningfully made for IvyCs, because of the low number of pairrecorded IvyCs that were tested for NPY $\left(n=3 \mathrm{IvyC}_{(\mathrm{NPY}+)}\right.$ of 3 tested for NPY, none of them from a MF-IvyC connected pair).

\section{GABAergic cells receive functionally different mossy fiber inputs}

Single MF-evoked EPSCs exhibited cell-type specificity in the functional domain as well (Fig. 7). Among the GABAergic cells postsynaptic to MFs, FSBCs and SLCs received MF-EPSCs with the lowest transmission probability (i.e., highest failure rate) (note that the probability of the failure is one minus the transmission probability), smallest amplitude of successful events (i.e., excluding failures) (Figs. $2 B, 3 B, 4 B$, and $5 B$; individual successful postsynaptic events are indicated by asterisks), and smallest amplitude of the euEPSCs (including successes and failures) (this measure thus depends on both the transmission probability and the amplitude of the successful events) during short bursts of presynaptic action potentials (summary data for responses to trains of 5 action potentials at $50 \mathrm{~Hz}$ are shown in Table 1 and supplemental Fig. 6, available at www.jneurosci.org as supplemental material). In contrast, RSBCs and IvyCs displayed the highest transmission probabilities, and the successful postsynaptic events showed the largest amplitudes during short bursts of presynaptic MF action potentials, resulting in the largest amplitude of MF-euEPSCs among all of the four GABAergic cell types that were found to be innervated by MFs (Table 1; supplemental Fig. 6, available at www.jneurosci.org as supplemental material) (note that there was no significant difference in the decay time constants of MF-EPSCs among the postsynaptic cell types). The relative weakness of the MF inputs to FSBCs and SLCs compared with RSBCs and IvyCs was evident in the euEPSCs even after single presynaptic spikes (Fig. $7 B$, Table 1).

Figure $8 \mathrm{~A}$ shows the averaged MF-EPSCs from all recorded cells. Note that, although certain cell type-specific trends may be apparent in the short-term plasticity properties of the MF responses, the trends in facilitation/depression in Figure $8 \mathrm{~A}$ for FSBCs, RSBCs, and IvyCs were not statistically significant. However, the facilitation in the transmission probabilities of MF responses in SLCs was statistically significant during longer trains ( 50 action potentials at $50 \mathrm{~Hz}$ ), as indicated by the asterisks in Figure $5 C$.

Together, the data in Figures 2-8 show that the innervation of FSBCs and SLCs by MFs is more numerous (i.e., more MF inputs per cell, as deduced from the observed probability of connections from the MF-GABAergic cell pair recordings) (Fig. 7A), but the MF-evoked responses are weaker (Fig. 7B) compared with RSBCs and IvyCs. These cell type-specific amplitude values for MF inputs cannot be caused by variabilities in recording conditions, as the series resistance of the postsynaptic recordings did not show significant differences among the four cell groups (FSBC: $15.5 \pm 2.3 \mathrm{M} \Omega$, RSBC: $16.3 \pm 5.2$ $\mathrm{M} \Omega$, IvyC: $18.9 \pm 2 \mathrm{M} \Omega$, SLC: $17.7 \pm 1 \mathrm{M} \Omega$ ) (note that these values were measured at the time when the MF-euEPSC data were recorded; also note that, because the GABAergic neuron was obtained first, followed by a search for connected MF boutons, the recordings from the GABAergic cells typically lasted for a prolonged period of time, up to $2 \mathrm{~h}$ ).

\section{Cell type-specific correlation between mossy fiber innervation and spontaneous synaptic inputs}

Interestingly, the functional specificity of CA3 GABAergic cells suggested by the apparent postsynaptic cell type-specific correlation between the different numbers (Fig. 7A) and strengths (Fig. $7 B$ ) of MF inputs is further supported by the differences in the frequency of spontaneous synaptic inputs to distinct types of 
GABAergic cells (Fig. $7 C_{1,2}$ ). Specifically, FSBCs and SLCs that were shown to receive a large number (Fig. 7A) of smallamplitude, low transmission probability (Figs. $2 B, 7 B, 8 A$ ) monosynaptic MF connections exhibited high-frequency spontaneous synaptic inputs (Fig. 7C; $76 \pm 11 \mathrm{~Hz}$ and $56.4 \pm 7.5 \mathrm{~Hz}$, respectively, $n=11$ cells for both cell types) (note that, because we intended to gauge the total incoming synaptic inputs to each of the four GABAergic cell types, these spontaneous events included both excitatory and inhibitory inputs). In contrast, RSBCs and IvyCs that were shown above to receive rare (Fig. 7A) but strong (Fig. 7B) MF inputs displayed significantly lower spontaneous event rates (Fig. 7C) $(26.5 \pm 4.5 \mathrm{~Hz}$ and $25.9 \pm 4.3 \mathrm{~Hz}$, respectively; $n=11$ for both) (Mann-Whitney nonparametric $U$ test revealed significant differences between FSBCs and RSBCs: $p=0.0009$, FSBCs and IvyCs: $p=0.0009$, RSBCs and SLCs: $p=0.0032$, and IvyCs and SLCs: $p=$ 0.0026 ; Fig. $7 B$, see asterisks). The postsynaptic cell type-specific correlation between the numbers and strength of MF inputs and the frequency of spontaneous inputs is highlighted in Figure $7 D$. These results were also supported by additional experiments with the type II metabotropic glutamate receptor agonist, DCG-IV, which is known to selectively decrease (albeit not abolish) action potential-dependent release of glutamate from MFs but not the local axon collaterals originating from CA3 pyramidal cells (Kamiya et al., 1996; Tóth and McBain, 1998). As expected from the data in Figure $7 A$ indicating frequent MF inputs to SLCs, DCG-IV had significantly attenuated the frequency of spontaneous events in SLCs compared with the pre-DCG-IV control baseline period ( $n=4$; relative decrease: $35.5 \pm 12 \%$; Student's $t$ test), whereas it failed to significantly change the event frequency in MFAs $(n=4$; relative decrease: $1.7 \pm 6.2 \%$ ), which appeared to be largely devoid of MF inputs (Fig. 7A).

Together, these data indicate cell type specificity (Fig. 8) of the connection probability (Fig. 7A) and strength (Fig. 7B) of the MF inputs, and the correlation of these two measures with the overall frequency of spontaneous synaptic inputs (Fig. 7C) that the GABAergic cells receive from the network.

\section{Discussion}

The results demonstrate that (1) MFs provide monosynaptic innervation to four distinct GABAergic cell types in CA3, including both perisomatically and dendritically projecting neurons; (2) MF targets in CA3 include GABAergic cells with intra- and extraCA3 projections; (3) the number and strength of MF inputs to CA3 GABAergic cells and the frequency of spontaneous synaptic events depend on the postsynaptic cell type, so that cells with a larger number of MF inputs receive more spontaneous synaptic events, but the MF inputs to these cells are relatively weak, whereas GABAergic cells receiving fewer but strong MF inputs display low spontaneous event frequencies.

\section{Pair recordings reveal diversity of CA3 GABAergic cells} innervated by granule cells

The DG-hippocampal interplay cannot be understood at the microcircuit level without precise knowledge of the GABAergic cell types that are monosynaptically excited by MFs. Several previous investigations provided insights into the nature of CA3 GABAergic cells innervated by MFs. GABAergic neuronal types within and adjacent to the stratum lucidum were shown to comprise both spiny and aspiny neurons (Spruston et al., 1997; Tóth and McBain, 1998). Furthermore, EM analysis of postsynaptic targets of in vivo labeled granule cells in the hilus and CA3 (Acsády et al., 1998) demonstrated that GABAergic postsynaptic targets included $\mathrm{PV}+$ profiles, and calretinin-immunoreactive and substance $\mathrm{P}$ receptor-immunoreactive $(\mathrm{SPR}+)$ neuronal elements (used as a marker for a subclass of GABAergic cells), indicating that GABAergic targets of MFs belong to more than a single type. The EM data also showed that spiny SPR + neurons with dendrites parallel to the MFs in stratum lucidum were the most frequently innervated by MFs (in agreement with our results with SLCs), and intracellularly labeled granule cell axons were found to contact PV + dendrites in the stratum lucidum (paralleling our results with FSBCs) (Acsády et al., 1998). Electrophysiological recordings of interneurons in the stratum lucidum combined with extracellular (often minimal) stimulation of the MF pathway indicated that the MF-evoked EPSCs showed heterogeneous plasticity properties among nonpyramidal cells (Maccaferri et al., 1998; Tóth and McBain, 1998; Toth et al., 2000; Lawrence et al., 2004), emphasizing the functional relevance of the diversity of GABAergic cells activated by MFs.

In previous studies, the MF origin of the evoked EPSCs in stratum lucidum nonpyramidal cells was determined based on the special sensitivity of the MF-EPSCs to DCG-IV. Here we used 
MF-GABAergic cell paired recording, combined with morphological and immunocytochemical identifications, to determine the components of the DG-CA3 interface. An advantage of our technique is that the relative probability of synaptic connections formed by MFs with identified GABAergic cells can be determined, and the method also allows verification of the association of presynaptic spikes with postsynaptic successes or failures, in contrast to extracellular minimal stimulation methods in which presynaptic action potentials cannot be reliably monitored. Therefore, we were able to determine the postsynaptic cell type specificity of unitary amplitudes and transmission probabilities of monosynaptic MF inputs. As our bouton-attached results indicate, the recording from giant MF terminals did not significantly alter the physiological properties of synaptic transmission between MFs and GABAergic cells [perhaps because the site of recording from the giant mossy fiber is at some distance from the actual site of transmitter release onto the recorded postsynaptic GABAergic cell; note that giant MF boutons occasionally synapse on GABAergic cells (Frotscher, 1985)].

In addition to supporting the MF innervation of FSBCs and SLCs (Acsády et al., 1998), our results, for the first time, demonstrate that MFs monosynaptically innervate RSBCs and IvyCs, and the single MF-DTC connected pair in our sample indicates that there is at least one more dendritically projecting GABAergic cell type that receives direct MF inputs. However, none of the simultaneously recorded MF-MFA pairs were monosynaptically connected, which is surprising given the preferential location of MFA axons within stratum lucidum (Vida and Frotscher, 2000), which suggests some type of association of MFAs with MFs. Although negative data should be interpreted with caution, and we cannot exclude the presence of some MF contacts on MFAs (note that MFA dendrites can cross the stratum lucidum) (Fig. 6), our results indicate that MFAs are unlikely to receive significant MF innervations, suggesting that the functional association of MFAs with MFs is more complex than simple feedforward inhibition driven by MFs.

\section{Target selectivity of MF innervation of CA3 basket cells}

The fact that both FSBCs and RSBCs receive monosynaptic excitation from MFs indicates that DG granule cells can engage the various basket cell functions attributed to these two nonoverlapping cell groups, i.e., the precise time-keeping roles of $\mathrm{PV}+$ basket cells (equivalent to our FSBCs) and the modulatory functions of CCK + basket cells (RSBCs) (Freund and Katona, 2007). However, because of marked differences in density and strength of MF inputs to FSBCs and RSBCs, it is likely that these basket cell types are sensitive to distinct aspects of granule cell activity. Because MF inputs to FSBCs are small and unreliable, and because these weak inputs arrive on a "noisy" synaptic background, individual action potentials in presynaptic granule cells may contribute relatively little to FSBC excitation. However, because FSBCs receive numerous MF inputs, they are likely to be better able to detect changes in average firing rates of a population of granule cells. In contrast, RSBCs may better integrate individual signals arising from a few granule cells, given the relatively strong and reliable but less numerous MF inputs that arrive on a less noisy background. It should be noted that, in contrast to our observations in the CA3 with MF inputs, Schaffer collateral EPSCs to FSBCs in CA1 are several times larger than those onto RSBCs (Gulyás et al., 1999; Glickfeld and Scanziani, 2006). It is currently unclear whether the latter apparent dissimilarity is attributable to differences between excitatory inputs (Schaffer collateral vs MF) or area-specific roles for distinct GABAergic cells. In any case, our data from CA3 FSBCs and RSBCs suggest that postsynaptic cell type-dependent mechanisms of synaptic excitation may underlie functionally distinct recruitment of different GABAergic neuronal types in the CA3 region by granule cells.

\section{MF inputs to SLCs and IvyCs}

Similar to FSBCs, SLCs also receive numerous MF inputs. The unique dendritic orientation of SLCs along the strata lucidum suggests that MFs may be a primary source of synaptic excitation in this septum-projecting GABAergic cell type (Wittner et al., 2006). The low initial transmission probability and the unique facilitation requiring numerous presynaptic spikes for significant MF-euEPSPs to emerge in SLCs suggest that the involvement of SLCs in the modulation of hippocampal theta oscillations, which is thought to be partly mediated by GABAergic projections to and from the medial septum (Freund and Antal, 1988; Tóth et al., 1997; Manseau et al., 2008), may preferentially take place during high levels of granule cell activity. Furthermore, the nature of the short-term plasticity of MF inputs to SLCs indicates that SLCs may be especially sensitive to the duration, and not simply the rate, of elevated granule cell firing.

IvyCs have been previously described only in CA1 (Fuentealba et al., 2008), where they were shown to be a numerically dominant interneuronal subtype specialized to innervate the basal and oblique pyramidal cell dendrites. As in CA1, our CA3 IvyCs exhibited delayed firing patterns with long AHPs, immunoreactivity to NPY, and fine, dense axonal arbors. As far as MF input properties are concerned, CA3 IvyCs were most similar to RSBCs, displaying rare but strong MF- euEPSCs on a background of lowfrequency spontaneous synaptic events. Although the properties of CA3 IvyCs will need to be studied further, it is likely that MF inputs to IvyCs contribute to the regulation of pyramidal cell dendritic excitability during behaviorally relevant network rhythms (Fuentealba et al., 2008) through slow IPSPs characteristic of neurons in the neurogliaform cell family (Tamás et al., 2003; Price et al., 2005; Szabadics et al., 2007).

\section{Complexity of the dentate-hippocampal GABAergic interface} In addition to the novel insights into the functional organization of the DG-CA3 GABAergic interface discussed above, our results also reveal several additional clues. First, 3 of 11 FSBCs in CA3 exhibited dual innervations of both CA3 and DG principal cell layers. Since two of these FSBCs with back-projections to the granule cell layer received MF inputs, these results indicate that granule cells may evoke both feedforward and feedback inhibition through the same individual CA3 GABAergic neuron. Second, our data indicate that GABAergic mechanisms that may shape the highly efficient activation of CA3 pyramidal cells on short bursts of repetitive granule cell discharges ("conditional detonator") (Henze et al., 2002; see also Lawrence and McBain, 2003) may involve cell type-specific, differential engagement of perisomatic and dendritic GABAergic synapses within CA3, as well as the GABAergic modulation of extrahippocampal areas. Future research will be needed to clarify how the target cellspecific excitation of CA3 GABAergic neurons by MFs contribute to the storage and recall of information and pattern separation during normal behaviors (Nakazawa et al., 2002; Bischofberger et al., 2006a; Leutgeb et al., 2007; Nakashiba et al., 2008), and to the special vulnerability of certain CA3 GABAergic cells (especially SLCs) after excitotoxic insults (Arabadzisz and Freund, 1999). 


\section{References}

Acsády L, Kamondi A, Sík A, Freund T, Buzsáki G (1998) GABAergic cells are the major postsynaptic targets of mossy fibers in the rat hippocampus. J Neurosci 18:3386-3403.

Arabadzisz D, Freund TF (1999) Changes in excitatory and inhibitory circuits of the rat hippocampus 12-14 months after complete forebrain ischemia. Neuroscience 92:27-45.

Bakker A, Kirwan CB, Miller M, Stark CE (2008) Pattern separation in the human hippocampal CA3 and dentate gyrus. Science 319:1640-1642.

Bischofberger J, Engel D, Frotscher M, Jonas P (2006a) Timing and efficacy of transmitter release at mossy fiber synapses in the hippocampal network. Pflugers Arch 453:361-372.

Bischofberger J, Engel D, Li L, Geiger JR, Jonas P (2006b) Patch-clamp recording from mossy fiber terminals in hippocampal slices. Nat Protoc 1:2075-2081.

Engel D, Jonas P (2005) Presynaptic action potential amplification by voltage-gated $\mathrm{Na}+$ channels in hippocampal mossy fiber boutons. Neuron 45:405-417.

Földy C, Neu A, Jones MV, Soltesz I (2006) Presynaptic, activity-dependent modulation of cannabinoid type 1 receptor-mediated inhibition of GABA release. J Neurosci 26:1465-1469.

Földy C, Lee SY, Szabadics J, Neu A, Soltesz I (2007) Cell type-specific gating of perisomatic inhibition by cholecystokinin. Nat Neurosci 10:1128-1130.

Freund TF, Antal M (1988) GABA-containing neurons in the septum control inhibitory interneurons in the hippocampus. Nature 336:170-173.

Freund TF, Buzsáki G (1996) Interneurons of the hippocampus. Hippocampus 6:347-470.

Freund TF, Katona I (2007) Perisomatic inhibition. Neuron 56:33-42.

Frotscher M (1985) Mossy fibres form synapses with identified pyramidal basket cells in the CA3 region of the guinea-pig hippocampus: a combined Golgi-electron microscope study. J Neurocytol 14:245-259.

Frotscher M, Jonas P, Sloviter RS (2006) Synapses formed by normal and abnormal hippocampal mossy fibers. Cell Tissue Res 326:361-367.

Fuentealba P, Begum R, Capogna M, Jinno S, Márton LF, Csicsvari J, Thomson A, Somogyi P, Klausberger T (2008) Ivy cells: a population of nitricoxide-producing, slow-spiking GABAergic neurons and their involvement in hippocampal network activity. Neuron 57:917-929.

Geiger JR, Jonas P (2000) Dynamic control of presynaptic Ca(2+) inflow by fast-inactivating $\mathrm{K}(+)$ channels in hippocampal mossy fiber boutons. Neuron 28:927-939.

Glickfeld LL, Scanziani M (2006) Distinct timing in the activity of cannabinoid-sensitive and cannabinoid-insensitive basket cells. Nat Neurosci 9:807-815.

Gulyás AI, Miettinen R, Jacobowitz DM, Freund TF (1992) Calretinin is present in non-pyramidal cells of the rat hippocampus-I. A new type of neuron specifically associated with the mossy fibre system. Neuroscience 48:1-27.

Gulyás AI, Megías M, Emri Z, Freund TF (1999) Total number and ratio of excitatory and inhibitory synapses converging onto single interneurons of different types in the CAl area of the rat hippocampus. J Neurosci 19:10082-10097.

Hahn TT, Sakmann B, Mehta MR (2007) Differential responses of hippocampal subfields to cortical up-down states. Proc Natl Acad Sci U S A 104:5169-5174.

Hefft S, Jonas P (2005) Asynchronous GABA release generates long-lasting inhibition at a hippocampal interneuron-principal neuron synapse. Nat Neurosci 8:1319-1328.

Henze DA, Wittner L, Buzsáki G (2002) Single granule cells reliably discharge targets in the hippocampal CA3 network in vivo. Nat Neurosci 5:790-795.

Jinno S, Klausberger T, Marton LF, Dalezios Y, Roberts JD, Fuentealba P, Bushong EA, Henze D, Buzsáki G, Somogyi P (2007) Neuronal diversity in GABAergic long-range projections from the hippocampus. J Neurosci 27:8790-8804.

Jonas P, Major G, Sakmann B (1993) Quantal components of unitary EPSCs at the mossy fibre synapse on CA3 pyramidal cells of rat hippocampus. J Physiol 472:615-663.

Kamiya H, Shinozaki H, Yamamoto C (1996) Activation of metabotropic glutamate receptor type $2 / 3$ suppresses transmission at rat hippocampal mossy fibre synapses. J Physiol 493:447-455.
Kawaguchi Y, Kubota Y (1997) GABAergic cell subtypes and their synaptic connections in rat frontal cortex. Cereb Cortex 7:476-486.

Klausberger T, Marton LF, O’Neill J, Huck JH, Dalezios Y, Fuentealba P, Suen WY, Papp E, Kaneko T, Watanabe M, Csicsvari J, Somogyi P (2005) Complementary roles of cholecystokinin- and parvalbumin-expressing GABAergic neurons in hippocampal network oscillations. J Neurosci 25:9782-9793.

Lawrence JJ, McBain CJ (2003) Interneuron diversity series: containing the detonation-feedforward inhibition in the CA3 hippocampus. Trends Neurosci 26:631-640.

Lawrence JJ, Grinspan ZM, McBain CJ (2004) Quantal transmission at mossy fibre targets in the CA3 region of the rat hippocampus. J Physiol 554:175-193.

Leutgeb JK, Leutgeb S, Moser MB, Moser EI (2007) Pattern separation in the dentate gyrus and CA3 of the hippocampus. Science 315:961-966.

Losonczy A, Biró AA, Nusser Z (2004) Persistently active cannabinoid receptors mute a subpopulation of hippocampal interneurons. Proc Natl Acad Sci U S A 101:1362-1367.

Maccaferri G, Tóth K, McBain CJ (1998) Target-specific expression of presynaptic mossy fiber plasticity. Science 279:1368-1370.

Manseau F, Goutagny R, Danik M, Williams S (2008) The hippocamposeptal pathway generates rhythmic firing of GABAergic neurons in the medial septum and diagonal bands: an investigation using a complete septohippocampal preparation in vitro. J Neurosci 28:4096-4107.

Miles R (1990) Synaptic excitation of inhibitory cells by single CA3 hippocampal pyramidal cells of the guinea-pig in vitro. J Physiol 428:61-77.

Min MY, Rusakov DA, Kullmann DM (1998) Activation of AMPA, kainate, and metabotropic receptors at hippocampal mossy fiber synapses: role of glutamate diffusion. Neuron 21:561-570.

Mori M, Abegg MH, Gähwiler BH, Gerber U (2004) A frequencydependent switch from inhibition to excitation in a hippocampal unitary circuit. Nature 431:453-456.

Mori M, Gähwiler BH, Gerber U (2007) Recruitment of an inhibitory hippocampal network after bursting in a single granule cell. Proc Natl Acad Sci U S A 104:7640-7645.

Nakashiba T, Young JZ, McHugh TJ, Buhl DL, Tonegawa S (2008) Transgenic inhibition of synaptic transmission reveals role of CA3 output in hippocampal learning. Science 319:1260-1264.

Nakazawa K, Quirk MC, Chitwood RA, Watanabe M, Yeckel MF, Sun LD, Kato A, Carr CA, Johnston D, Wilson MA, Tonegawa S (2002) Requirement for hippocampal CA3 NMDA receptors in associative memory recall. Science 297:211-218.

Nakazawa K, McHugh TJ, Wilson MA, Tonegawa S (2004) NMDA receptors, place cells and hippocampal spatial memory. Nat Rev Neurosci 5:361-372.

Neu A, Földy C, Soltesz I (2007) Postsynaptic origin of CB1-dependent tonic inhibition of GABA release at cholecystokinin-positive basket cell to pyramidal cell synapses in the CA1 region of the rat hippocampus. J Physiol 578:233-247.

Nicoll RA, Malenka RC (1995) Contrasting properties of two forms of longterm potentiation in the hippocampus. Nature 377:115-118.

Nicoll RA, Schmitz D (2005) Synaptic plasticity at hippocampal mossy fibre synapses. Nat Rev Neurosci 6:863-876.

Pelkey KA, McBain CJ (2008) Target-cell-dependent plasticity within the mossy fibre-CA3 circuit reveals compartmentalized regulation of presynaptic function at divergent release sites. J Physiol 586:1495-1502.

Pelkey KA, Topolnik L, Lacaille JC, McBain CJ (2006) Compartmentalized $\mathrm{Ca}(2+)$ channel regulation at divergent mossy-fiber release sites underlies target cell-dependent plasticity. Neuron 52:497-510.

Price CJ, Cauli B, Kovacs ER, Kulik A, Lambolez B, Shigemoto R, Capogna M (2005) Neurogliaform neurons form a novel inhibitory network in the hippocampal CA1 area. J Neurosci 25:6775-6786.

Rollenhagen A, Sätzler K, Rodriguez EP, Jonas P, Frotscher M, Lübke JH (2007) Structural determinants of transmission at large hippocampal mossy fiber synapses. J Neurosci 27:10434-10444.

Salin PA, Scanziani M, Malenka RC, Nicoll RA (1996) Distinct short-term plasticity at two excitatory synapses in the hippocampus. Proc Natl Acad Sci U S A 93:13304-13309.

Spruston N, Lübke J, Frotscher M (1997) Interneurons in the stratum lucidum of the rat hippocampus: an anatomical and electrophysiological characterization. J Comp Neurol 385:427-440. 
Szabadics J, Tamás G, Soltesz I (2007) Different transmitter transients underlie presynaptic cell type specificity of GABAA,slow and GABAA,fast. Proc Natl Acad Sci U S A 104:14831-14836.

Takács VT, Freund TF, Gulyás AI (2008) Types and synaptic connections of hippocampal inhibitory neurons reciprocally connected with the medial septum. Eur J Neurosci 28:148-164.

Tamás G, Lorincz A, Simon A, Szabadics J (2003) Identified sources and targets of slow inhibition in the neocortex. Science 299:1902-1905.

Tóth K, McBain CJ (1998) Afferent-specific innervation of two distinct AMPA receptor subtypes on single hippocampal interneurons. Nat Neurosci 1:572-578.

Tóth K, Freund TF, Miles R (1997) Disinhibition of rat hippocampal pyramidal cells by GABAergic afferents from the septum. J Physiol 500:463-474.
Toth K, Suares G, Lawrence JJ, Philips-Tansey E, McBain CJ (2000) Differential mechanisms of transmission at three types of mossy fiber synapse. J Neurosci 20:8279-8289.

Vida I, Frotscher M (2000) A hippocampal interneuron associated with the mossy fiber system. Proc Natl Acad Sci U S A 97:1275-1280.

Williams SH, Johnston D (1991) Kinetic properties of two anatomically distinct excitatory synapses in hippocampal CA3 pyramidal neurons. J Neurophysiol 66:1010-1020.

Wittner L, Henze DA, Záborszky L, Buzsáki G (2006) Hippocampal CA3 pyramidal cells selectively innervate aspiny interneurons. Eur J Neurosci 24:1286-1298.

Ylinen A, Soltész I, Bragin A, Penttonen M, Sik A, Buzsáki G (1995) Intracellular correlates of hippocampal theta rhythm in identified pyramidal cells, granule cells, and basket cells. Hippocampus 5:78-90. 